\title{
HR ANALYTICS AND ITS MODERATING FACTORS
}

This theoretical paper elaborates the moderating factors of Human Resource Analytics (HR Analytics), which is seen as one of the top initiatives in HR today. It seems that analytics is taking the guesswork out of the decision-making process by offering a more data-driven approach. Although HR Analytics holds a high priority for most organizations, the implementing process is slow and only a minor proportion of organizations even even reports applying it. HR Analytics is not making progress as it is proposed by many academics in the last 10 years. Therefore, it seems to be necessary to identify the moderating factors of HR Analytics that promote or prevent its success. The number of academic research articles dealing with this topic is very low. The impact of moderating factors on the level of HR Analytics is vague and remains unexplored. This paper offers potential explanations for the relationship between the moderating factors and HR Analytics and provides suggestions for organizations on how to best address these factors. Within the first section of this paper the development and theoretical assumptions of a more data-driven approach to decision-making in HR is elaborated. Next, the concept of HR Analytics is going to be defined. The third section illustrates case studies and takes a look on how widespread the practice of HR Analytics in organizations already is. In the following each moderating factor is going to be examined in detail. Finally, the major findings of the topic under review are discussed and summarized.

\section{Keywords: HR Analytics, People Analytics, HR Metrics, Big Data, Strategic HRM}

$\mathrm{I}_{\mathrm{c}}^{\mathrm{t}}$ seems that analytics is taking guesswork out of the decision-making process in the HR function. While most hiring, promotion and reward decisions are based on intuition, HR Analytics offers a more data-driven approach to making those decisions. The notion of measuring data in the HR function is not new. The pioneer Jac Fitz-enz already published a book on How to Measure Human Resources Management in 1984, emphasizing the need for measurements in the HR function. However, it took more than 30 years until the idea of applying big data in HR became an area of high interest. With his article in 2010 Competing on Talent Analytics, Thomas Davenport introduced an era with a lot of articles and papers heralding the start of applying big data in HR and describing how it would revolutionize the HR landscape. At that time, Dave Ulrich argued in his paper Are We There Yet? What's Next for $H R$, that the status of HR is more related to administrative and compliance duties. Nowadays, HR Analytics holds a high priority for the companies surveyed in a study by Deloitte (2015). However, progress is slow and according to another study only about 16 percent of organizations even report applying HR Analytics (CedarCrestone's 17th Annual HR Systems).

The purpose of this paper is to address the question why HR Analytics is not making progress as it is proposed by many academics. In doing so, this paper provides a review of high quality research, related to moderating factors that promote or prevent the success of HR Analytics. However, high quality research in regards to the value of HR Analytics is quite rare. On the one hand, most of the articles are published by consultants with a business interest and more based on believe than evidence. On the other hand, most of the reported HR Analytics success stories have a narrow focus and deal with topics like turn- over. The purpose of this paper is not only to identify and describe moderating factors of HR Analytics. It further aims to provide a better understanding on how moderating factors influence the level of HR Analytics and to show how organizations best address these factors.

\section{Methodology}

The literature review is based on the inclusion of research journal papers, books, white papers and consulting reports, dealing with the concept of HR Analytics and specifically with factors that seem to have an impact on the successful use of HR Analytics in organizations. The review was conducted using academic databases accessed through EBSCOhost and Google Scholar using the keywords HR Analytics, Human Resource Analytics, People Analytics, Talent Analytics, and Workforce Analytics. A total of 39 articles were added to the literature review, which were - with two exceptions - all published between the years 2004-2017. It is notable, that 33 out of the 39 articles were published from 2010 on, along with the publicity of Google's HR Analytics project Oxygen and the publication of the article Competing on Talent Analytics by Thomas Davenport. Although 22 of the 39 referenced articles were published in management research journals, the research revealed that there are many more consulting reports, white papers and blogs dealing with the concept HR Analytics. Hence, the topic under review does not seem to be of great importance for the management researchers. This results in a predominance of non-empirical articles. The majority of the referenced articles in this literature review are of non-quantitative empirical nature, only four articles involve testing of theoretically derived hypotheses. 
The analysis of the articles revealed five main directions of moderating factors in regards to HR Analytics. For better transparency, they have been given the following names in this literature review: (1) identify problems, (2) data infrastructure, (3) information technology, (4) analytical skills, (5) enterprise approach. In order to ensure a better understanding of the topic under review, the literature review also covers the background of HR Analytics and elaborates the development and theoretical assumptions of a more data-driven approach to decision-making in HR. This is followed by an elaboration of existing definitions of HR Analytics. Further, case studies are illustrated in order to show how widespread the practice of HR Analytics in organizations already is. Finally, the major findings of the topic under review are discussed and summarized. Table 1. summarizes the details of the most important articles referenced in the literature review in regards to the topics covered.

\section{Background of HR Analytics}

The term human resource management (HRM) comprises the traditional core activities such as resource staffing, planning, performance appraisal, training and devel- opment, compensation, labor relations, and safety and health. Besides these activities, HRM includes aligning these HR activities, managing organizational change and culture, and organizational design activities as part of its strategic role (Schuler-Jackson, 2005). The role of HRM evolved greatly since the 1980 s and has changed from the role of an administrator of mandatory HR practices to a more strategic role by acting as a strategic business partner (Ulrich-Dulebohn, 2015). The evolution of HRM has mainly been affected by the development of new technologies, which have changed the different HR processes and the way the work is managed and done in organizations (Stone et al., 2015). This overall development of HRM has had a significant impact on the practice and the overall focus of HRM. When looking back in the administrative role of HRM, its main objective was to make HR practices more cost-effective. However, since HRM takes over a strategic role the objective is more related to generating value for the overall organizational business, for instance by improving customer satisfaction through enhanced employee engagement (Ulrich - Dulebohn, 2015).

The term strategic human resource management signals the belief that effective HRM has a positive impact on business effectiveness (Jackson et al., 2014). The stra-

\section{Details of most relevant articles}

Table 1.

\begin{tabular}{|c|c|c|c|c|}
\hline Authors & Background of HR Analytics & Definition of HR Analytics & HR Analytics in practice & Moderating factors of HR Analytics \\
\hline $\begin{array}{l}\text { Marler and Boudreau } \\
\text { (2017) }\end{array}$ & $\begin{array}{l}\text { HR Analytics is relatively new and } \\
\text { at the early adopters stage. The } \\
\text { notion of HR Analytics appeared } \\
\text { with the introduction of talent } \\
\text { management applications }\end{array}$ & $\begin{array}{l}\text { Practice enabled by IT that uses } \\
\text { descriptive, visual, and statistical } \\
\text { analyses of data related to HR } \\
\text { processes, human capital, } \\
\text { organizational performance, and } \\
\text { external economic benchmarks to } \\
\text { establish business impact and enable } \\
\text { data-driven decision-making }\end{array}$ & & $\begin{array}{c}\text { Analytical skills of HR professionals } \\
\text { Management buy-in } \\
\text { HR information technology }\end{array}$ \\
\hline Pape, T. (2016) & $\begin{array}{l}\text { Data-driven approach to HRM to } \\
\text { improve decision-making process }\end{array}$ & $\begin{array}{c}\text { HR Analytics as a decision process based } \\
\text { on data analyses }\end{array}$ & & Data collection \\
\hline $\begin{array}{l}\text { Ulrich and Dulebohn } \\
\text { (2015) }\end{array}$ & $\begin{array}{l}\text { Development of HR from an } \\
\text { administrative to a strategic role }\end{array}$ & & & $\begin{array}{l}\text { HR should be connected to the } \\
\text { broader organizational business } \\
\text { context }\end{array}$ \\
\hline $\begin{array}{l}\text { Rasmussen and Ulrich } \\
\text { (2015) }\end{array}$ & $\begin{array}{l}\text { Data-driven approach to HRM to } \\
\text { improve decision-making process }\end{array}$ & HR Analytics is a fad & & $\begin{array}{c}\text { Business understanding of } \mathrm{HR} \\
\text { managers }\end{array}$ \\
\hline Levenson, A. (2013) & $\begin{array}{c}\text { Wider perspective of } \mathrm{HR} \text { as the } \\
\text { basis for the decision-making } \\
\text { process and to create strategic } \\
\text { value }\end{array}$ & & & $\begin{array}{l}\text { Data collection } \\
\text { Effective use of data } \\
\text { Strategic data analysis }\end{array}$ \\
\hline Aral et al. (2012) & & $\begin{array}{l}\text { Measuring and monitoring individual } \\
\text { performance }\end{array}$ & $\begin{array}{l}\text { Positive correlation between financial } \\
\text { performance and use of HR Analytics }\end{array}$ & HR information technology \\
\hline Bassi, L. (2011) & $\begin{array}{l}\text { The development of HR metrics } \\
\text { and information technology has } \\
\text { created new possibilities for } \\
\text { business intelligence on the } \\
\text { people side }\end{array}$ & $\begin{array}{l}\text { Evidence-based approach for making } \\
\text { better decisions on the people side of } \\
\text { the business; it consists of an array of } \\
\text { tools and technologies, ranging from } \\
\text { simple reporting of HR metrics all the } \\
\text { way up to predictive modelling }\end{array}$ & & $\begin{array}{c}\text { Data availability } \\
\text { Analytical skills of HR professional }\end{array}$ \\
\hline Coco et al. (2011) & & & $\begin{array}{c}\text { Positive correlation between HR Analytics } \\
\text { and employee engagement, HR processes } \\
\text { and business performance }\end{array}$ & Management buy-in \\
\hline Levenson, A. (2011) & & $\begin{array}{l}\text { HR Analytics as a way to improve the } \\
\text { decision-making process }\end{array}$ & $\begin{array}{l}\text { Positive correlation between financial } \\
\text { performance and use of HR Analytics }\end{array}$ & $\begin{array}{c}\text { Analytical skills of HR professionals } \\
\text { Management buy-in }\end{array}$ \\
\hline Mondore et al. (2011) & & $\begin{array}{l}\text { Demonstrating that people have a } \\
\text { direct impact on the business } \\
\text { performance }\end{array}$ & $\begin{array}{l}\text { Positive correlation between financial } \\
\text { performance and use of HR Analytics }\end{array}$ & Analytical skills of HR professionals \\
\hline Lawler et al. (2004) & $\begin{array}{l}\text { Data processing, measuring and } \\
\text { analyzing as the basis for decision- } \\
\text { making process in HRM }\end{array}$ & $\begin{array}{l}\text { Represents statistical and experimental } \\
\text { techniques that are used to } \\
\text { demonstrate the effect of HR activities } \\
\text { on the performance of a company }\end{array}$ & & $\begin{array}{c}\text { Analytical skills of HR professionals } \\
\text { HR information technology }\end{array}$ \\
\hline
\end{tabular}


tegic role of HRM is based on the assumption that it links HRM to the organizational business environment and thus helps organizations to achieve objectives related to the strategic business and profitability (Schuler, 2013; Walsh et al., 2010). The development of strategic HRM is closely connected to the broader concept of strategic management, which has been affected by the global trend that business decisions should consider the external environment (Jackson et al., 2014). In line with this reasoning, Ulrich and Dulebohn (2015) propose that HRM should not only be linked to the narrow organizational business, but also be connected to various stakeholders and the broader business context of the organization. Hence, in addition to the employees, HRM needs to understand the customer behavior and business processes. This broader perspective constitutes the basis for the decision-making process and enables the HR function to create greater value by aligning its objectives and activities to the environment the organization is operating in (Levenson, 2013).

The major evolution HRM has made over time, along with the technological development, greatly impacts the measurement and decision-making processes of HRM. Similarly, many scholars argue that data processing, measuring and analyzing as the basis for decision-making process in HRM constitute the key factors in the development of HRM to a strategic partner (Lawler et al., 2004; Walsh, 2010). However, although this development is well-recognized, uncertainty is associated with the business impact of HRM, as a gap of respective research results is still existing in the literature (Boudreau - Ramstad, 2007; Walsh, 2010; Jackson et al., 2014). Indeed, compared to other functions like finance and marketing, HR is lacking proper analytical tools and metrics for the decision-making process and is thus left behind in producing strategic value (Lawler et al., 2004). A data-driven approach to HRM is perceived as a possible way to address this problem, enabling decisions based on evidence instead of intuition or personal experience (Lawler et al., 2004; Rasmussen - Ulrich, 2015; Pape, 2016). However, when examining the literature more closely it has to be noted that concepts surrounding the notion of evidence-based decision-making in HRM are still not fully established.

The idea of measuring data in HR is not new and developed almost simultaneously with the changing role of HRM. Metrics on measuring cost, quantity and time of workforce already emerged in the 1970s. In the 1980s, these metrics began to include benchmarking, which allowed organizations to compare their results with other organizations (Fitz-enz, 2010). Later on in the 1990s balanced scorecards and strategy maps were developed to include operational targets and strategic goals of the organizations. Typically, the HR balanced scorecards included HR outcomes and processes, alignment between the processes and the business strategy, and KPIs measuring the effectiveness of the HR outcomes and processes (Douthitt - Mondore, 2014). HR metrics are usually divided into four types, including effectiveness metrics, efficiency metrics, and impact or outcome metrics (Lawler et al., 2004; Boudreau - Ramstad, 2007). Boudreau and
Ramstad (2007) claim that HRM has mainly been engaged in measuring the efficiency of the HR function itself, instead of providing measurements indicating the value it generates for the overall business. Although the focus is still strongly on HRM itself, measurements have already shifted from activities towards the outcomes, along with the development of strategic HRM. In order to deliver more strategic value, HR will need to be able to show correlations between its activities and business outcomes (Ulrich-Dulebohn, 2015).

\section{Definition of HR Analytics}

The process of applying big data in HR has been given different names, including HR Analytics, People Analytics, Talent Analytics, and Workforce Analytics. Just as with the name, no uniform definition of HR Analytics exists (Marler-Boudreau, 2017). A first definition approach distinguishes HR Analytics from HR metrics and states that it represents statistical and experimental techniques that are used to demonstrate the effect of HR activities on the performance of a company (Lawler et al., 2004). Later on, the definitions of HR Analytics become more generally and describe it as a process that either focuses on analysis or on decision-making. According to Harris et al. (2011), HR Analytics consists of six different types of analytical processes for analyzing HR data. Falletta (2014) defines HR Analytics in terms of 18 HR practices. Her research shows that employee surveys are predominant, followed by talent profiling and HR metrics. Mondore et al. (2011) take a more strategic approach and define HR Analytics as demonstrating that people have a direct impact on the business performance.

Bassi (2011, p. 16.) probably reports the most comprehensive definition until the middle of this decade by stating that HR Analytics 'is an evidence-based approach for making better decisions on the people side of the business; it consists of an array of tools and technologies, ranging from simple reporting of HR metrics all the way up to predictive modelling'. This definition considers that HR Analytics includes the idea of reporting important HR metrics, generating more ambitious solution concepts supported by predictive modelling and adopting an evidence-based approach to the decision-making process. Marler and Boudreau (2017, p. 15.) go one step further by defining HR Analytics as 'a HR practice enabled by information technology that uses descriptive, visual, and statistical analyses of data related to HR processes, human capital, organizational performance, and external economic benchmarks to establish business impact and enable data-driven decision-making'. This definition emphasizes the strategic role of HR Analytics as it goes beyond reporting HR metrics and connects HR decisions and processes with organizational performance. These HR decisions and processes are not only based on sophisticated analysis of HR data, but involve data from different internal functions and even external data. The analysis of the data requires respective information technology and employees with the necessary skills. 
The discussion of the definition characterizes HR Analytics as an innovation in the subject area of human resource management (HRM). Hence, it is too early to estimate whether it becomes an established institutional HRM practice or disappears when its expectations are not realized (Marler - Boudreau, 2017). The future development of HR Analytics may, to some extent, depend on moderating factors that promote or prevent the success of it. Some of them were already raised in the discussion of the characteristics of it. For instance, an innovation that links HR decisions with organizational performance requires the involvement of the top management of the organization. As HR Analytics collects and analyses not only HR data but also data from other internal functions and data external to the organization, a whole enterprise approach is needed. A sophisticated analysis of the data requires respective technology that is applied by employees with the right skills. Finally, the information analyzed itself has to be comprehensive and of good quality.

\section{HR Analytics in Practice}

Aral et al. (2012) present strong evidence for a positive correlation between financial performance and the use of HR Analytics in their empirical study. In addition, several non-empirical articles confirm this correlation with illustrative case studies (Harris et al., 2011; Coco et al., 2011; Mondore et al., 2011; Levenson, 2011; DiBernardino, 2011). For instance, Harris et al. (2011) describe how Sysco performs HR Analytics to determine connections between higher revenue, delivery driver employee satisfaction, work climate surveys and customer loyalty. Further, they illustrate how Google uses their applicant database to predict the individual level of performance. By providing a detailed case study, Coco et al. (2011) show how Lowes, a home improvement retail chain, performs HR Analytics in order to establish a link between employee engagement, HR processes and store performance. Through higher employee engagement they were able to increase the average customer ticket sales per store by 4 percent.

Given this evidence, which supports the assumed positive link between HR Analytics and business performance, it is surprising that there is still a low level of HR Analytics across the companies. In line with that reasoning, Falleta (2014) surveyed 220 Fortune 1000 firms to determine the use of HR Analytics. She discovered that for only 15 percent of the sample HR Analytics played a key role in defining or introducing the HR strategy. Beyond that, the primarily HR Analytics activity was analyzing results of employee questionnaires. Lawler and Boudreau (2015) report in a similar study, which surveyed more than 100 Fortune 500 firms, that less than 30 percent of the firms have HR Analytics that determines the correlation between HR processes, employees and business impact. However, more than 70 percent of the firms use HR metrics to show how efficient their HR processes are. This allocation of HR resources is questionable when considering that administrative costs typically only represent 3 percent of a company's selling. Thus, reducing HR administrative expenses is unlikely to have any impact on business performance (Harris et al., 2011).

\section{Moderating Factors}

\section{Identify problems}

The mathematician John W. Tukey (1962, p. 13.) stressed that 'an approximate answer to the right question, which is often vague, [is far better] than an exact answer to the wrong question, which can always be made precise'. This notion is relevant in a way that it helps HR Analytics to become the desired innovation as expected by many academics and practitioners, and to avoid just being another management fad. Rasmussen and Ulrich (2015) argue that an extensive analysis of a large amount of data and trying to answer the wrong questions will have little practical value. In order to deliver value to the organization, the ability is needed to go beyond just identifying patterns and to initiate and execute the entire organizational change process. This requires HR managers to have a clear business understanding and focus, who are at the moment in short supply (Rasmussen - Ulrich, 2015).

Fink (2017) suggests that an end-to-end HR Analytics work flow starts with asking the right question and ends with measuring the result to determine whether the action was effective. However, the Chartered Institute for Personnel and Development (2013) argues that HR professionals do not have enough knowledge, skills and business insight to ask the right question based on the data that is available to them. Moreover, even if HR professionals do have good and promising approaches related to analytics, their hierarchical position within the organization may hinder their initiatives from being realized (Smeyers, 2015).

\section{Data infrastructure}

Harris et al. (2011) stress the importance of having consistent, accurate, integrated, relevant and accessible employee data available in order to track employee competencies and reveal patterns. Bersin (2013) points out that the availability of HR data is not an issue since organizations have captured educational history, demographic and performance information, and many other employee factors since around three decades. However, the full potential of HR Analytics can only be exploited when data across functions and even external to the organization are combined. Likewise, Rasmussen and Ulrich (2015) emphasize that HR Analytics is more likely to reveal new insights when different perspectives and fields (e.g. customers, investors, technology, human capital, etc.) are combined. Hence, any limitation in regards to data and information restricts the potential of HR Analytics.

In contrast to the statement by Bersin, data availability is an issue. On the one hand researchers report that data are not fully collected or inaccurate (Bassi, 2011; Angrave et al., 2016; Pape, 2016) On the other hand, the required data is not fully accessible as it is not integrated across functions, divisions or geographies (Douthitt-Mondore, 2014). As a result, generated reports and conducted anal- 
yses are very basic and only reflect insufficient efficiency-based metrics (Falletta, 2014). According to Angrave et al. (2016), this situation might change when information technology vendors see HR Analytics as a new innovation to increase their profits. Then, human resource information systems (HRIS) would improve in regards to functionality and ability to integrate data from different sources.

\section{Information technology}

The importance of HRIS for HR Analytics is noted by several articles. Indeed, Aral et al. (2012) demonstrated in their study that organizations with HR Analytics, but without HRIS show no performance improvement. In relation to HR Analytics, information technology can be both an enabler and an obstacle. Good HRIS act as an enabler for HR Analytics, when they capture and store data, and make accessible data across functions, divisions or geography to generate reports, scorecards and dashboards (Marler-Boudreau, 2017). However, as mentioned previously, current HRIS capabilities do not meet the requirements of HR Analytics.

The latest development in HRIS is the talent development suite, which is an integration of different HR processes, including recruitment, performance management, learning and development, and compensation management. According to Bersin (2014), a global market of 6 billion US-Dollars was estimated for this kind of product. The key players dominating this market are Oracle, IBM, SAP and Workday. By making it easier to access, operate and understand the relevant HR data, the primary purpose of their type of HRIS is to improve HR processes (Angrave et al., 2016). Hence, they can be used as a basis for HR Analytics as they capture, store and report HR-relevant data and metrics. However, anything that goes beyond in the direction of advanced analytics requires information technology that focuses on data exploration, analysis and modeling.

According to a study by Kaur and Fink (2017), the most used technologies for HR Analytics include R, Tableau, Python, SPSS and Excel. The study confirms that HRIS are not sufficient enough to conduct statistical analysis and data visualization. The most frequent tool used is $\mathrm{R}$, which is favored because of its compatibility with many file formats and other tools like Tableau, and also offers several machine learning packages. The used technology already implicates that HR Analytics requires advances statistical and econometric skills that exceed the correlation analysis of dependent and independent variables.

\section{Analytical skills}

The lack of HR professionals with analytical skills is probably the most common reason cited in the literature why HR Analytics does not become more widespread. However, even analytical people need statistical or econometric software like R or Stata. The analytics packages that can be added to the standard HRIS do not have the power and flexibility to test through analysis of experiments that assumptions about correlations between specific variables derive from certain causalities (Cascio
- Boudreau, 2011). Bassi (2011) proposes, that the HR function will lose responsibility in regards to analytics to the IT and Finance function, if it does not have the skills to use analytic information technology tools and to obtain and use measures of business results. Angrave et al. (2016) elaborate this concern and stress, that the human capital input into the business will be fundamentally misunderstood, if the HR function is not fully participating in the modelling process.

In order to effectively perform HR Analytics HR professionals need specific analytical competencies. These include data preparation, research design, root cause analysis, quantitative data collection, data analyses, and multivariate models (Levenson, 2011). This is a complex process, which needs to be translated into an understandable result so that the top management can base their decisions upon it (Angrave et al., 2016). Levenson et al. (2005) report in their study that a high level of statistical skills is not in high demand in the HR function. However, there is even an insufficient supply at this low level. HR Analytics professionals with advanced statistics skills only represent one third of their profession. This proportion drops to three percent when only considering HR professionals not hired for HR Analytics.

The opinion on the question whether academics can support to close the gap between HR professionals and data scientists of an already existing business analytics projects is divided. The involvement of academics in corporate analytics projects has been reported in many articles (Sparrow et al., 2015; Cascio-Boudreau, 2011). There is evidence of organizations drawing on the expertise of PhDs in occupations like engineering, statistics and psychology to enhance their analytics activities (Bersin, 2015). In contrast, Rasmussen and Ulrich (2015) question their business understanding to ask the right question. They even go one step further and suggest taking HR Analytics out of HR in order to become part of cross-functional end-to-end business analytics.

\section{Enterprise approach}

The next moderating factor of HR Analytics is culturally and politically based. The successful implementation and performance of HR Analytics is characterized by changes and will thus demand high flexibility and adaptability from the whole organization. In this regards, Rasmussen and Ulrich (2015) highlight Festinger's findings on cognitive dissonance. According to Festinger, there is a strong bias towards rejecting information that pose a risk to existing convictions, especially if they have invested effort, time and identity in their ideas or projects. Therefore, HR Analytics success depends on overcoming such resistance by involving key stakeholders in the process ahead of conducting the analysis. HR Analytics is not just about data and science but also about activism and change management (Rasmussen - Ulrich, 2015).

Davenport and Harris (2007) call for a culture that is open to analytics and with an organization-wide acknowledgement of measuring, testing and evaluating quantitative data. This would in turn urge employees to take 
decisions in a highly rational way. The analytical approach should be included in the company strategy and be pushed down to every company level. That is why the success of HR Analytics is in large part depending on the top- and middle management of an organization. Waber (2015) stresses, that 'you do need buy-in from leadership' (p. 3) when implementing HR Analytics. A culture is needed and has to be promoted by the leadership that tolerates experimentation and errors, which currently does not seem to be tolerated, especially in the HR function (Davenport et al., 2010).

A whole enterprise approach is required with the integration of processes, data and analysis throughout the company (Harris et al., 2011). As HR Analytics requires gaining access to cross functional data, managers from other functions must be involved in the process and willing to provide access to the data. Davenport and Harris (2007) suggest that all data-collection and actions in this regards should be under the control of one common management. Such a project needs to be managed by people with the skills to manage changes in processes, behaviors and culture triggered by analytic initiatives (Harris et al., 2011). That is why HR professionals must build credibility among the top management who may not believe in datadriven results by the HR function.

\section{Discussion and Conclusions}

The elaboration of the moderating factors of HR Analytics provide some possible explanations on why HR Analytics is not making progress as it is proposed in the literature. Overall five main moderating factors have been identified in the literature that promote or prevent the success of HR Analytics. Most of the articles are theoretically based and provide limited scientific evidence concerning the practical implementation and application of HR Analytics. Current research is dominated by qualitative case studies drawing on already existing management frameworks at a very broad general level. That is why even leading researchers do not agree on HR Analytics to be the next 'must have' innovation in the HR function. Hence, there is still much room for academic researchers to contribute to the development of the concept HR Analytics, especially through scholarly scientific research.

The development during the past four decades shows that the HR function takes over a more strategic role. Along with advanced information technology, this development is mainly based on more sophisticated HR measurements and metrics that improve the decision-making process. However, practitioners will have to overcome certain obstacles on which a successful implementation of HR Analytics is depending on. Among the main obstacles are HR professionals who do not understand analytics or big data and analytics specialists who do not understand HR. Consequently, even the latest costly forms of HRIS, which provide analytics capabilities, are failing to contribute to the achievement of strategic HR Analytics objectives. A different and more comprehensive approach is needed to avoid HR Analytics just being a management fad. In this regards, the five moderating factors identified in the literature appear to play a significant role and to have an impact on the success of HR Analytics.

First, HR professionals need to be able to identify organizational problems and to ask the right questions. Analyzing a large amount of data trying to answer the wrong question will most likely damage the interests of employees instead of being beneficial. Second, HR Analytics requires an infrastructure that makes accurate and consistent data across functions and even external to the organization accessible. Third, information technology is needed that goes in the direction of advanced analytics and focuses on data exploration, analysis and modeling. Most of the current HRIS capabilities do not meet these requirements and need to be upgraded. Next, in order to effectively perform HR Analytics HR professionals need specific skills to prepare the data, conduct statistical analysis and communicate the results in a meaningful and understandable way. In this regards, the deployment of academics can support to close the gap between HR professionals and data scientists of an already existing business analytics projects. Indeed, some organizations are already drawing on the expertise of PhDs in occupations like engineering, statistics and psychology to enhance their analytics activities. Finally, in order to implement HR Analytics effectively, a whole enterprise approach is needed with the integration of processes, data and analysis throughout the organization. This demands high flexibility and adaptability from the whole organization, which has to be managed in a change management process.

In conclusion, despite being a new area of high interest, which is discussed by many academics and industry professionals, only a small amount of scientific research exists. The reason might be the innovative nature of HR Analytics, which is lacking a scientific research approach. The development of an integrated, strategic framework on how to implement and operate HR Analytics would reduce the uncertainty early-adopters are facing at this early stage. This review helps to better understand the relationship between important contextual factors and the successful adoption of HR Analytics. However, further research is needed to better evaluate the impact of these factors.

\section{References}

Angrave, D. - Charlwood, A. - Kirkpatrick, I. - Lawrence, M. - Stuart, M. (2016): HR and analytics: Why HR is set to fail the big data challenge. Human Resource Management Journal, Vol. 26, pp. 1-11.

Aral, S. - Brynjolfsson, E. - Wu, L. (2012): Three-way complementarities: Performance Pay, human resource analytics, and information technology. Management Science, Vol. 58, pp. 913-931.

Bassi, L. (2011): Raging debates in HR Analytics. People \& Strategy, Vol. 34, pp. 14-18.

Bersin, J. (2013): Big Data in Human Resources: Talent Analytics (HR Analytics) Comes of Age. Source: https://www.forbes.com/sites/joshbersin/2013/02/17/ 
bigdata-in-human-resources-talent-analytics-comesof-age/\#280ea53f4cd0 2018. 02. 20

Bersin, J. (2014): Talent Management for the Global Workforce: The Market for Talent Management Systems 2014. Oakland, CA: Bersin by Deloitte.

Bersin, J. (2015): The geeks arrive in HR: people analytics is here. Source: https://www.forbes.com/ sites/joshbersin/2015/02/01/geeks-arrive-in-hr-peopleanalytics-is-here/\#6ab42d8273b4 2018. 02. 20

Boudreau, J. - Ramstad, P. (2007): Beyond HR. The new science of human capital. Boston: Harvard Business School Press

Cascio, W. - Boudreau, J. (2011): Investing in people: Financial impact of human resource initiatives. New Jersey: by Pearson Education, Inc.

CIPD (2013): Talent Analytics and Big Data - The Challenge for HR, London: Chartered Institute for Personnel and Development. Source: https://www.cipd. co.uk/Images/talent-analytics-and-big-data_2013challenge-for-hr_tcm18-9289.pdf 2018. 02. 20

Coco, C. T. - Jamison, F. - Black, H. (2011): Connecting people investments and business outcomes at Lowe's: Using value linkage analytics to link employee engagement to business performance. People \& Strategy, Vol. 34, pp. 28-33.

Davenport, T. H. - Harris, J. G. (2007): Competing on Analytics: The New Science of Winning. Boston: Harvard Business School Press

Davenport, T. H. - Harris, J. - Shapiro, J. (2010): Competing on talent analytics. Harvard Business Review, Vol. 88, pp. 52-58.

DiBernardino, F. (2011): The missing link: Measuring and managing financial performance of the human capital investment. People \& Strategy, Vol. 34, pp. 44-49.

Douthitt, S. - Mondore, S. (2014): Creating a businessfocused HR function with analytics and integrated talent management. People \& Strategy, Vol. 36, pp. $16-21$.

Falletta, S. (2014): In search of HR intelligence: Evidencebased HR Analytics practices in high performing companies. People \& Strategy, Vol. 36, pp. 28-37.

Fink, A. A. (2017): Getting results with talent analytics. People + Strategy Journal, Vol. 40, No. 3.

Fitz-enz, J. (2010): The new HR Analytics: Predicting the economic Value of Your Company's Human Capital Investments. New York: Amacom Books

Fitz-enz, J. (1995): How to measure human resources management. New York: McGraw-Hill

Harris, J. G. - Craig, E. - Light, D. A. (2011): Talent and analytics: New approaches, higher ROI. Journal of Business Strategy, Vol. 32, pp. 4-13.

Jackson, S. - Schuler, R. - Jiang, K. (2014): An aspirational framework for strategic human resource management. The academy of management annals, Vol. 8, pp. 1-56.

Kaur, J. - Fink, A. A. (2017): Trends and practices in talent analytics. Society for Human Resource Management (SHRM)-Society for IndustrialOrganizational Psychology (SIOP) Science of HR White Paper Series. Source: http://www.siop.org/SIOP-
SHRM/2017\%2010_SHRM-SIOP\%20Talent $\% 20$ Analytics.pdf 2018. 02. 20

Lawler III, E. E. - Levenson, A. - Boudreau, J. W. (2004): HR metrics and analytics: Use and Impact. Human Resource Planning, Vol. 27, pp. 27-35.

Lawler III, E. E. - Boudreau, J. W. (2015): Global trends in human resource management: A twenty year analysis. Stanford: Stanford University Press.

Levenson, A. (2013): The promise of big data for HR. People \& Strategy, Vol. 36, pp. 22-26.

Levenson, A. (2011): Using targeted analytics to improve talent decisions. People \& Strategy, Vol. 34, pp. 34-43.

Levenson, A. - Lawler III, E. E. - Boudreau, J. W. (2005): Survey on HR Analytics and HR transformation: Feedback report. Los Angeles: Center for Effective Organizations, University of Southern California

Marler, J. H. - Boudreau, J. W. (2017): An evidence-based review of talent analytics. The International Journal of Human Resource Management, Vol. 28, No. 1, pp. $3-26$.

Mondore, S. - Douthitt, S. - Carson, M. (2011): Maximizing the impact and effectiveness of HR Analytics to drive business outcomes. People \& Strategy, Vol. 34, pp. 20-27.

Pape, T. (2016): Prioritizing data items for business analytics: Framework and application to human resources. European Journal of Operational Research, Vol. 252, pp. 687-698.

Rasmussen, T. - Ulrich, D. (2015): Learning from practice: How HR Analytics avoids being a management fad. Organizational Dynamics, Vol. 44, pp. 236-242.

Schuler, R. (2013): Opportunities abound in HRM and innovation. Journal of Chinese Human Resource Management Vol. 4, pp. 121-127.

Schuler, R. - Jackson, S. (2005): A quarter-century review of human resource management in the U.S.: the growth in importance of the international perspective. Management Revue, Vol. 16, pp. 1-25.

Smeyers, L. (2015): What We Learned about HR Analytics in $2014-$ part 2 .

Sparrow, P. - Hird, M. - Cooper, C. (2015): Do We Need HR? Repositioning People Management for Success. Basingstoke: Palgrave Macmillan

Stone, D. - Deadrick, D. - Lukaszewski, K. - Johnson, $R$. (2015): The influence of technology on the future of human resource management. Human Resource Management Review, Vol. 25, pp. 216-231.

Tukey, J. W. (1962): The future of data analysis. Annals of Mathematical Statistics, Vol. 33, No. 1, pp. 1-67.

Ulrich, D. - Dulebohn, J. (2015): Are we there yet? What's next for HR? Human Resource Management Review, Vol. 25, pp. 188-204.

Waber, B. (2013): HR Analytics: How Social Sensing Technology Will Transform Business And What IT Tells Us about the New World of Work. New Jersey: Pearson Education, Inc.

Walsh, K. - Sturman, M. (2010): Key issues in strategic human resources. The Scholarly Commons. School of Hotel Administration Collection 